\title{
Promoting Global Health: The World Association of Medical Editors Position on Editors' Responsibility*
}

We live in a world community. Our countries are interconnected in ways unanticipated by previous generations. This new reality means that global health can only be achieved through collaboration, cooperation, and sharing of resources across boundaries. Global health has been defined in several ways and we draw attention to one of these: "Global health is an area for study, research, and practice that places a priority on improving health and achieving equity in health for all people worldwide. Global health emphasizes transnational health issues, determinants, and solutions; involves many disciplines within and beyond the health sciences and promotes interdisciplinary collaboration; and is a synthesis of population-based prevention with individual-level clinical care."(1)

Published medical research is a global public good. For their part as members of a world community, editors of medical journals have a social responsibility to publish quality research on global health. Some important peer-reviewed journals are devoted exclusively to global health, but editors of general medical and health specialty journals also have a social responsibility to publish quality research on global health. Editors, editorial boards, and publishers must realize the importance of identifying, measuring and understanding global health concerns, including their burden, determinants, patterns, and impact, as well as solutions and successes to improve health and create necessary change. The importance of these concepts should be reflected in their pages. Research and commentary must address not only the clinical presentation and epidemiological features of health and disease across the globe but also the social and political realities that jeopardize the advancement of health and well-being of people and countries, including political unrest, compromised health and public health systems, and social, economic, cultural and environmental factors.
The World Association of Medical Editors (WAME), a voluntary global organization of medical journal editors, is uniquely positioned to define the critical role that editors have to play in promoting global health. In its 20 years of existence, WAME has sought to facilitate worldwide cooperation and communication among editors of peer-reviewed medical journals, improve editorial standards, and promote professionalism in medical journal editing. Its membership comprises 1915 members representing more than 1000 journals from 92 countries (2) and represents a greater breadth of medical editors than any other professional organization. Therefore, in May 2015, WAME issued its statement on promoting global health (Appendix A).

How should an editor meet this social responsibility? He or she must, whenever possible, publish research that furthers health worldwide [especially addressing the greatest global health concerns (3)] that meets the journal's standards for research quality, regardless of where the research was conducted and irrespective of the gender, race and ethnicity of the authors. Papers that describe and analyze the global health concerns in terms of disease burden, determinants, patterns, impacts and the like are important, but editors need to also encourage publications that are innovative and solution-focused, including research with negative results. Editors need to be mindful that low- and middle-income countries (LMIC) often have the greatest health burdens, and therefore encourage research from authors in those geographic areas. Editors should not change their quality criteria, but they should recognize that some authors for whom English is not the primary language may need assistance in polishing manuscripts for publication and provide constructive feedback and assistance if possible.

Editors need to invite researchers in LMIC to be peer reviewers so that the relevant global health context is consid-

\footnotetext{
*Cite the original published version as:

Winker MA, Ferris LE, WAME Ethics and Policy Committee, WAME Board. Promoting Global Health: The World Association of Medical Editors Position on Editors' Responsibility. World Association of Medical Editors. May 26, 2015.http://www.wame.org/Resource/Details/5.

Important editorial note:

The editor of the Balkan Medical Journal (Cem Uzun) is a member of the World Association of Medical Editors and believes it is important that the statement on promoting global health and this accompanying editorial is brought to the attention of readers. This Editorial may appear in other medical and biomedical journals whose editors are members of WAME. The World Association of Medical Editors (WAME) retains copyright [http://www.wame.org/].
} 
ered. The process of peer review of global health research, whether or not a specific peer-reviewed manuscript is ultimately accepted, should be viewed as an educational process for authors, reviewers, and editors alike. The publishing of quality global health research, and helping to develop expertise of researchers, peer reviewers, academicians, clinicians, as well as editors, is the ultimate goal. Editors in high-income countries should invite researchers and global health leaders in LMIC to join their editorial boards. Board members should help encourage the submission of global health research from LMIC and help the journal in meeting its social responsibility. Researchers and others in LMIC should be invited to write editorials and commentaries; these articles can address the regional impact of research and should help educate readers in high-income countries about the human costs and consequences of global health issues.

We do not expect or want editors to publish poor or questionable research because such research will not advance global health; indeed it may actually harm it. Thus, the WAME statement endeavors to make clear that editors should publish, whenever possible, research that furthers global health, and that the editor's responsibility is to promote global health by using the best editorial practices to ensure quality publishing.

Journals in LMIC may become disadvantaged if highquality global health research is published primarily in large international journals. Large international journals should be aware of this issue and develop innovative ways to disseminate the research to potential readers in LMIC in "real time". For example, these international journals could facilitate the publication in national journals of related research such as pre-planned subgroup analyses of the study relevant to a specific country or population, sharing confidential pre-embargo documents and not applying copyright restrictions to republication of properly designated overlapping portions of the study. International journals also could enable pre-publication access to a study to allow regional journals to publish timely commentaries on the implications of a study, thereby reaching different audiences. International journals should in turn refer to and cite the commentary in national journals to convey to readers the impact of global health research in the countries it is intended to benefit.

High quality scholarship can best advance global health when it is made available globally. Editors should work with publishers to ensure that LMIC have free web-based access to relevant papers. The 2002 World Health Organization initiative HINARI (4) is the free option that many subscriptionbased journals opt for and provides a superior alternative to no free access. However, HINARI provides access via institutions to staff and students only, rather than directly to individuals; institutions in Group B middle-income coun- tries must pay an annual fee; and some large middle-income countries such as India, Pakistan, Indonesia, and China are excluded due to business considerations. Furthermore, HINARI countries may be selectively removed from access by individual publishers (5). Therefore, we encourage journals to ensure whenever possible that all individuals in LMIC have free access to their content. Journals with publication fees should offer waivers to researchers from LMIC. Publishers should support editors in these efforts as they share responsibility for global health.

Many editors and journals are already leaders in promoting global health. We can learn from their expertise and experiences, and all can strive to find new and innovative ways to promote global health. The purpose of this statement is to highlight that all medical journal editors have a role to play: the medical research literature is a global public good and promoting global health is a global social responsibility.

Acknowledgements: We thank Dr Peter Singer from Grand Challenges Canada for his input on early versions of the WAME Global Health Principles.

\section{REFERENCES}

1. Koplan JP, Bond T, Merson M, Reddy K, Rodriguez M, Sewankambo N. Towards a common definition of global health. Lancet 2009;373(9679):1993-5. DOI: 10.1016/ S01406736(09)60332-9. Also available at https://www.globalbrigades. org/media/Global_Health_Towards_a_Common_Definitition. pdf. Accessed April 28, $20 \overline{15}$.

2. What is WAME? World Association of Medical Editors. http:// www.wame.org/about. Accessed April 14, 2015.

3. Global burden of disease. World Health Organization. http:// www.who.int/topics/global_burden_of_disease/en/ Accessed April 14, 2015.

4. HINARI Access to Research in Health Programme. World Health Organization. http://www.who.int/hinari/en/ Accessed April 17, 2015.

5. Koehlmoos, TP; Smith R. Big publishers cut access to journals in poor countries. Lancet 377(9762); 273 - 276. http:// www.thelancet.com/journals/lancet/article/PIIS01406736\%2811\%2960067-6/fulltext. Accessed April 282015.

\section{Margaret A. Winker \\ Secretary \\ World Association of Medical Editors, Winnetka, IL, USA}

\section{Lorraine E. Ferris}

President

World Association of Medical Editors; Professor in the Dalla Lana School of Public Health, University of Toronto (Canada) 


\author{
The World Association of Medical Editors (WAME) \\ Ethics and Policy Committee, and the WAME Board \\ The following members of the WAME Ethics and Policy Com- \\ mittee and WAME Board authored this document in addition \\ to those explicitly named in the byline (listed alphabetically):
}

Rakesh Aggarwal, Virginia Barbour, Michael Callaham, Phaedra E. Cress, Farrokh Habibzadeh, Fatema Jawad, Rajeev Kumar, Christine Laine, Tom Lang, Glenn McGee, Hooman Momen, Rod J. Rohrich, Maria del Carmen Ruiz, Peush Sahni, Elizabeth Wager.

Appendix A

\section{WAME Statement on Promoting Global Health}

The published medical research literature is a global public good. Medical journal editors have a social responsibility to promote global health by publishing, whenever possible, research that furthers health worldwide. For purposes of this statement, global health is defined as follows: "Global health is an area for study, research, and practice that places a priority on improving health and achieving equity in health for all people worldwide. Global health emphasizes transnational health issues, determinants, and solutions; involves many disciplines within and beyond the health sciences and promotes interdisciplinary collaboration; and is a synthesis of population-based prevention with individual-level clinical care.” (1)

More specifically, all medical journal editors, regardless of their location, should strive to:

(a) Publish research addressing the greatest global health concerns;

(b) Specifically encourage the publication of innovative and solution-focused research in all fields of medicine, public health, and health promotion; in particular, research applicable to low- and middle-income countries;

(c) Encourage the publication of research from authors in low- and middle-income countries;

(d) Provide free Web-based access to research articles to readers in countries that cannot afford to pay for them;

(e) Provide publication fee waivers for research conducted and authored primarily by researchers from low- and middle-income countries; and,

For editors in high-income countries:

(f) Invite researchers from low- and middle-income countries to participate on editorial boards of their journals;

(g) Invite researchers from low- and middle-income countries to participate as peer reviewers for articles submitted to their journals;

(h) Invite researchers from low-and middle-income countries to write editorials and commentaries on the local or regional impact of and, if relevant, responses to global health issues to help educate readers in high-income countries about the human costs and consequences of these issues.

\section{REFERENCES}

1. Koplan JP, Bond T, Merson M, Reddy K, Rodriguez M, Sewankambo N. Towards a common definition of global health. Lancet 2009;373(9679):1993-5. DOI: 10.1016/ S0140-6736(09)60332-9. Also available at https://www.globalbrigades.org/media/Global_ Health_Towards_a_Common_Definitition.pdf.

This Statement has been approved by the WAME Ethics and Policy Committee and endorsed by the WAME Board (May 31, 2015). 